\title{
Frequency of germline hereditary non-polyposis colorectal cancer gene mutations in patients with multiple or early onset colorectal adenomas
}

\author{
N E Beck, ${ }^{\star}$ I P M Tomlinson, ` T F R Homfray, I M Frayling, S V Hodgson, W F Bodmer
}

\begin{abstract}
Background-The hereditary nonpolyposis colorectal cancer (HNPCC) syndrome is caused by germline mutations in mismatch repair genes and predisposes individuals to cancers of the colon and other specific sites. On theoretical grounds, it is expected that patients with HNPCC also develop more colorectal adenomas than the general population. In essence, if the mutation rate is raised owing to mutations at a mismatch repair locus, more mutations are expected at loci such as APC (adenomatous polyposis coli) and more adenomas will start to grow. Not all data support this expectation, however. Aim-To search for germline mutations at HNPCC loci in patients with multiple adenomas.
\end{abstract}

Subjects-Twenty five patients (without known APC mutations) who have developed colorectal adenomas in unusually large numbers and, in some cases, at an early age.

Methods-Germline APC mutations were excluded using the protein truction test for exon 15 and mismatch chemical cleavage analysis for remaining exons. Germline HNPCC mutations were detected by using PCR and single strand conformation polymorphism analysis.

Results-Just one germline HNPCC mutation was found (4\% of cases) and this was of uncertain functional effect.

Conclusions-In general, germline HNPCC mutations are not responsible for the phenotype of patients with multiple colonic adenomas. It is possible that patients with HNPCC tend to develop adenomas more frequently and earlier than the general population, but that this effect is relatively subtle. These results suggest that individuals with colorectal adenomas only should not strictly be classified as "affected" in HNPCC families (although they should certainly not be classified as "unaffected" either and may warrant intensive screening). In the absence of a personal or strong family history of colorectal cancer, it is probably not worthwhile performing diagnostic or predictive genetic testing for HNPCC mutations in subjects with colorectal adenomas. Although undetected APC mutations may be responsible for some of the phenotypes in this sample, as yet uncharacterised adenoma predisposing genes probably exist.

(Gut 1997; 41: 235-238)
Keywords: hereditary non-polyposis colorectal cancer syndrome; hMSH2; hMLH1; colorectal adenomas

The hereditary non-polyposis colorectal cancer (HNPCC) syndrome is a disease with dominant inheritance which predisposes to colorectal and various extra-colonic cancers. HNPCC is caused by germline mutations at one of at least four loci (hMSH2, hMLH1 and, less commonly, hPMS1 and hPMS2). ${ }^{1}$ All these genes are involved in DNA mismatch repair. In HNPCC cancers, somatic mutation is thought to inactivate the wild type mismatch repair allele, leading to defective DNA repair. ${ }^{2}$

The great majority of colorectal cancers probably develop from adenomas and HNPCC mutations are said to exert their effects by increasing the mutation rates in tissues such as the colonic epithelium. Patients with HNPCC would therefore be expected to have an increased frequency of colorectal adenomas, as well as carcinomas. If, as seems likely, two mutations at the APC locus are required to initiate adenoma growth, ${ }^{3}$ patients with HNPCC should have more cells which acquire two APC mutations, and hence more adenomas. These theoretical predictions are borne out by experiments showing that Msh2 deficient mice develop more adenomas than mice with normal mismatch repair alleles. ${ }^{4}$

It is apparent that any excess of colonic adenomas in HNPCC does not resemble the thousands of adenomas seen in classic familial adenomatous polyposis (FAP). ${ }^{15}$ This difference between FAP and HNPCC is easily explained by the fact that patients with FAP carry one germline APC mutation and a suitable cell need only acquire one somatic APC mutation to cause an adenoma; in the simplest situation in HNPCC, the cell must acquire one somatic mismatch repair mutation and two somatic APC mutations - albeit faster than normal if the mismatch repair mutations increase the mutation rate-before an adenoma grows. Clearly, adenomas are likely to be much more frequent in FAP than in HNPCC.

More surprisingly, however, Jass et al have shown that patients with HNPCC develop no more colonic adenomas than the general population. Their data were obtained by comparing the frequency and anatomical distribution of adenomas in at-risk members of HNPCC pedigrees with postmortem controls. The conclusions of Jass et al suggest that patients with HNPCC adenomas differ from those of the general population in their more frequent and faster progression to cancer, but 
not in their frequency. If true, it is a matter of great interest to determine why germline HNPCC mutations affect tumour progression, but not initiation.

Some features of HNPCC do, however, support the theoretical expectation that patients with HNPCC develop more colonic adenomas than the general population. For example, some HNPCC cancers occur at a very young age, sometimes at less than 20 years old, ${ }^{78}$ when the frequency of adenomas in the general population is thought to be very low. ${ }^{6}$ Moreover, occasional families have included carriers of HNPCC mutations who have developed phenotypes like the attenuated form of FAP (AAPC). ${ }^{9}$ It is also suggested by some studies that the replication errors (RERs) characteristic of double mismatch repair mutants can occur in early colorectal adenomas, implying that the HNPCC loci have been involved in the initial stages of adenoma growth. ${ }^{10}$

Confirming or refuting the data of Jass et $a l^{6}$ is important for understanding the biology of adenomas and HNPCC cancers. It is also important clinically, for, if adenoma formation is the rate-limiting step in the growth of HNPCC cancers, it may be possible to screen for colorectal tumours at relatively long intervals in HNPCC families. The ideal way to resolve the problem of adenomas in HNPCC is to determine adenoma frequency in individuals undergoing colonoscopic screening for a family history of colon cancer. In those kindreds subsequently shown to have germline HNPCC mutations, the frequency of adenomas in mutation carriers and non-carriers could be compared within each family, thus providing relatively well matched cases and controls.

If HNPCC does predispose to adenomas, via a raised mutation rate, adenomas will tend to occur earlier and more frequently in carriers of germline HNPCC mutations. Some patients with HNPCC will, by chance, develop several or multiple adenomas, or adenomas of early onset. Another strategy for studying adenoma formation in HNPCC families is therefore to determine the frequency of germline HNPCC mutations in such patients. We have investigated 25 patients with varying numbers of colorectal adenomas who have been investigated for FAP and AAPC, but in whom no germline APC mutations have been found. Single strand conformation poylmorphism (SSCP) analysis has been used to screen the hMSH2 and hMLH1 genes for germline mutations in these patients. Mutations in these genes account for up to $90 \%$ of all HNPCC families and our results thus suggest whether or not HNPCC predisposes to colorectal adenomas as well as cancers.

\section{Methods}

Patients were enrolled initially from individuals presenting to or referred to St Mark's Hospital, London, who had been found on colonoscopy to have multiple adenomas of a number suggestive of AAPC (generally <100), but without the florid polyposis of FAP $(>100$ adenomas, but usually many more). Details of the proband's past history of colon tumours or previous colonoscopies, or both, were obtained from the patient and/or from the medical notes/histopathology reports. Any family history of colorectal or other tumours was acquired similarly. After obtaining informed consent for the purposes of research only, peripheral blood or normal tissue was collected from each patient (table 1) for the aim of studying the APC gene and other genes involved in colorectal tumorigenesis. DNA was extracted from these samples using standard techniques.

Germline APC mutations were excluded using the protein truncation test ${ }^{11}$ for exon 15 and mismatch chemical cleavage analysis (for the remaining exons). The search for germline mutations HNPCC mutations was then undertaken. Each of the 16 exons of hMSH 2 and the 19 exons of hMLHI (mutations in which account for $>90 \%$ of HNPCC) was amplified specifically using the polymerase chain reaction (PCR). ${ }^{12}$ SSCP analysis was used to detect mutations, with PCR products run on $10 \%$ acrylamide:bisacrylamide $(30: 0.8)$ gels run at $20 \mathrm{~mA}$ for $18-24$ hours and products detected by silver staining. For all cases with SSCP bandshifts suggestive of mutations, two independent PCR products were sequenced alongside control samples, using the Applied Biosystems (Foster City, California, USA) Ready Reaction Dye Terminator Cycle Sequencing kit and a 377 fluorescence based, semiautomated DNA sequencer.

\section{Results}

Table 1 shows the clinical features of the patients studied. Excluding individuals with "multiple" adenomas, the median number of colonic adenomas present was 15 (range 1 to $\geqslant 100$ ). Probands presented at a median age of 51 years (range 19-78). Twelve (48\%) patients had more than 10 adenomas, $10(40 \%)$ had several $(<10)$ adenomas and three $(12 \%)$ had "multiple" adenomas. Four (16\%) patients were considered to have had early onset disease ( $<35$ years). Twenty $(80 \%)$ patients presented with a known family history of colorectal tumours and one (4\%) patient had desmoid disease, a feature associated with FAP. Seven $(28 \%)$ of the sample had developed colorectal carcinoma, in addition to their adenomas.

We detected a germline HNPCC mutation in just one patient. This individual (patient no. 3) presented at age 19 with about 50 adenomas and was not known to have a family history of colorectal tumours. Subsequent DNA sequencing showed an ATC to GTC missense mutation in codon 219 (exon 8) of the hMLHI gene. This results in substitution of the amino acid valine for isoleucine. These amino acids have similar lipophilic side chains and the functional effect of this mutation is questionable. Germline variants at this site have been detected both in patients with HNPCC and apparently normal individuals. ${ }^{2}{ }^{13}$ It is not yet clear whether this variant has an effect on the risk of colorectal tumours. 
TABLE 1 Clinical features of patients studied

\begin{tabular}{|c|c|c|c|c|c|c|c|c|}
\hline \multirow[b]{2}{*}{ No. } & \multirow[b]{2}{*}{$\operatorname{Sex}$} & \multirow{2}{*}{$\begin{array}{l}\text { Age at } \\
\text { diagnosis }\end{array}$} & \multirow{2}{*}{$\begin{array}{l}\text { Colorectal } \\
\text { adenomas }^{a}\end{array}$} & \multirow{2}{*}{$\begin{array}{l}\text { Colorectal } \\
\text { cancer }(s)\end{array}$} & \multirow{2}{*}{$\begin{array}{l}\text { Family } \\
\text { history of } \\
\text { colorectal } \\
\text { tumours }\end{array}$} & \multicolumn{3}{|c|}{ Relatives with malignancy of any site or other colorectal tumours ${ }^{b}$} \\
\hline & & & & & & First degree & Second degree & Third degree \\
\hline 1 & $\mathrm{~F}$ & 41 & $100+$ & 0 & $\mathrm{Y}$ & 1: Co & $\begin{array}{l}\text { 3: } \mathrm{Br} ; \mathrm{Ga} \mathrm{Co}+\mathrm{Co}+\mathrm{Ads} \\
\text { (3)+En }\end{array}$ & $\begin{array}{l}\text { 2: Co+Ads (3); Ads } \\
\text { (?) }\end{array}$ \\
\hline 2 & M & 31 & 24 & 0 & $\mathrm{Y}$ & 2: $\mathrm{Co}+\mathrm{Ga} ; \mathrm{Co}$ & 1: Co & \\
\hline 3 & $\mathrm{~F}$ & 19 & $50-100$ & 0 & $\mathrm{~N}$ & & 1: Oe & \\
\hline 4 & $\mathrm{~F}$ & 59 & $5^{c}$ & 1 & $\mathrm{~N}$ & & & \\
\hline 5 & $M$ & 55 & 70 & 0 & $\mathrm{Y}$ & 2: Co; Ads (?) & & \\
\hline 6 & $\mathrm{~F}$ & 35 & $3,3,1,0,4,0$ & 0 & $\mathrm{Y}$ & 1: Co & 1: Lu & \\
\hline 7 & $M$ & 45 & "Multiple" & 1 & $?$ & & & \\
\hline 8 & $\mathrm{~F}$ & 57 & 70 & 1 & $\mathrm{Y}$ & 3: $\mathrm{Co} ; \mathrm{Ga} ; \mathrm{Ca}$ n/s & & \\
\hline 9 & $\mathrm{~F}$ & 49 & $1,14,1,2$ & 3 & $\mathrm{Y}$ & 1: Co & & \\
\hline 10 & $\mathrm{~F}$ & 78 & $50+$ & 0 & $\mathrm{Y}$ & 2: Co; Ads (?) & 1: Ads (?) & \\
\hline 11 & $\mathrm{~F}$ & 29 & $30-40$ & 0 & $?$ & & & \\
\hline 12 & M & 63 & $\begin{array}{l}\text { 1, "Multiple", 1, } \\
1,1\end{array}$ & 0 & $\mathrm{Y}$ & 1: Co & 3: Co; Co; Ads (?) & 1: Co+Ads (?) \\
\hline 13 & M & 65 & $1^{\mathrm{d}}$ & 0 & $\mathrm{Y}$ & 3: $\mathrm{Co}+\mathrm{Co}+\mathrm{Co} ; \mathrm{GI}$; $\mathrm{Ca}$ n/s & $1: \mathrm{Ga}$ & \\
\hline 14 & M & 56 & $12,2,1$ & 1 & $\mathrm{Y}$ & $\begin{array}{l}\text { 7: } \mathrm{Co} ; \mathrm{Co} ; \mathrm{Co} ; \mathrm{Co} ; \mathrm{Co}+\mathrm{Pa}+\mathrm{Ads} \\
\text { (20); } \mathrm{Pa} \text {; Ads (6) }\end{array}$ & $\begin{array}{l}\text { 6: Co+Ads (4); Ads (8); } \\
\text { Ad; Ads (6); Ki+Ad; } \mathrm{Br}\end{array}$ & 2: Ad; Ad \\
\hline 15 & M & 52 & "Multiple" & 0 & $\mathrm{~N}$ & 3: $\mathrm{Co} ; \mathrm{Co} ; \mathrm{Vu}$ & 1: Co & \\
\hline 16 & $\mathrm{~F}$ & 57 & $7,5,1,4,1$ & 2 & $\mathrm{Y}$ & 1: B1 & & \\
\hline 17 & M & 46 & $1,1,1,4$ & 0 & $\mathrm{Y}$ & 3: Co; Ads (?); Ads (?) & & \\
\hline 18 & $M$ & 54 & $1^{\mathrm{e}}$ & 0 & $\mathrm{Y}$ & 1: Co & $2: \mathrm{Br} ; \mathrm{Ca} \mathrm{n} / \mathrm{s}$ & \\
\hline 19 & $\mathrm{~F}$ & 63 & $40-50$ & 0 & $\mathrm{Y}$ & 3: $\mathrm{Co} ; \mathrm{Co} ; \mathrm{Ca} \mathrm{n} / \mathrm{s}$ & 1: Ca n/s & 1: $\mathrm{Ca} \mathrm{n} / \mathrm{s}$ \\
\hline 20 & M & 50 & 0 & 0 & $\mathrm{Y}$ & 1: Co & & \\
\hline 21 & $M$ & 51 & 6 & 0 & $\mathrm{Y}$ & 2: Co; Co & 3: $\mathrm{Co} ; \mathrm{Co} ; \mathrm{Ca}$ n/s & \\
\hline 22 & $M$ & 60 & 3 & $2^{\mathrm{f}}$ & $\mathrm{Y}$ & 2: En; $\operatorname{Pr}$ & 4: $\mathrm{Co} ; \mathrm{Co} ; \mathrm{Br} ; \mathrm{NHL}$ & $1: \mathrm{Br}$ \\
\hline 23 & $\mathrm{~F}$ & 48 & 4 & 0 & $\mathrm{Y}$ & 2: $\mathrm{Pa} ; \mathrm{Lu}$ & 4: $\mathrm{Co} ; \mathrm{Br} ; \mathrm{Me} ; \mathrm{Lk}$ & \\
\hline 24 & M & 49 & 6 & 0 & $\mathrm{Y}$ & 2: Co; Ads (?) & 1: Co & $1: \mathrm{Ga}$ \\
\hline 25 & M & 51 & 4 & 0 & $\mathrm{Y}$ & $\begin{array}{l}\text { 4: Ads (?); Ads (?); Ads (?); Ads } \\
\text { (?) }\end{array}$ & 2: Ads (?); Ads (?) & \\
\hline $26^{\mathrm{g}}$ & $\mathrm{F}$ & 63 & $1^{\mathrm{h}}$ & 0 & $\mathrm{Y}$ & 2: $\mathrm{Co} ; \mathrm{Co}$ & 1: $\mathrm{Lu}^{\mathrm{i}}$ & \\
\hline $27^{\mathrm{g}}$ & $\mathrm{F}$ & 29 & 0 & $0^{j}$ & $\mathrm{~N}$ & & & \\
\hline
\end{tabular}

aEither (i) total number of adenomas found or (ii) if separated by commas, numbers of adenomas removed on successive occasions, or (iii) "multiple" if exact number of adenomas not reported, but with notes or personal comunication indicating that the number of adenomas lay within the range consistent with a diagnosis of AAPC.

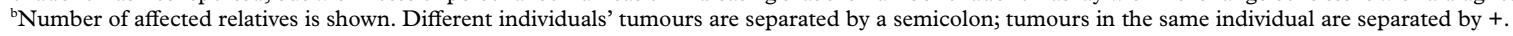

Cancer types: Co, colorectal; Br, breast; Pr, prostate; Lu, bronchus; Lk, leukaemia; Ki, kidney (RCC); NHL, non-Hodgkin's lymphoma; Bl, urinary bladder (TCC); $\mathrm{Me}$, melanoma; $\mathrm{Vu}$, vulva; Oe, oesophagus; $\mathrm{Pa}$, pancreas; En, endometrium; GI, gastrointestinal; Ca n/s, cancer site not specified/unknown; Ads, colorectal adenomas, with total numbers in parentheses; (?) indicates multiple adenomas, but precise number not known.

cAlso multiple intra-abdominal desmoid tumours.

d“Upper GI polyposis" also noted.

${ }^{e}$ Mucinous adenoma of the appendix; patient studied owing to unusual tumour suggestive of precursor of HNPCC.

fSynchronous cancers of duodenum, caecum, and sigmoid colon.

'Patients additional to sample of 25 , studied owing to unusual tumours.

${ }^{\text {h}}$ Serrated adenoma.

${ }^{\mathrm{i}}$ Carcinoid tumour.

'Multiple desmoid tumours in leg and back.

\section{Discussion}

We have detected a very low frequency of germline mutations in patients with several, multiple or early onset adenomas. Of a total of 25 cases, one hMLH1 variant of uncertain functional effect was detected; no hMSH2 mutants were found. It is possible that SSCP analysis did not detect all hMSH2 and hMLHI variants present in our sample. Some point mutations tend to be difficult to detect using SSCP and a small number of patients with HNPCC have mutations, such as whole exon deletions, that cannot be analysed using SSCP. ${ }^{14}$ We estimate that SSCP will detect about $60 \%$ of all germline HNPCC mutants. ${ }^{15-19}$ We did not use RERs as a way of assessing our patients' tumours for two reasons. Firstly, tumour material was only available from a minority of patients. Secondly, although RERs can be used as an initial screen for germline HNPCC mutations, adenomas can acquire RERs owing to two somatic mutations at HNPCC loci and this reduces the effectiveness of RER screens in patients with multiple tumours. Thirdly, and most importantly, there is uncertainty regarding the stage at which HNPCC and sporadic adenomas become RER positive. ${ }^{1020}$

Our sample only included seven patients in whom one or more adenomas had progressed to colorectal cancer. None of these patients had detectable $\mathrm{hMSH} 2$ or hMLHI variants. In general, however, germline HNPCC mutations may be more prevalent in such patients and cause rapid progression of adenomas. In our sample, the relative absence of malignant lesions may, to some extent, have selected out carriers of HNPCC mutations. It is possible that patients with HNPCC usually do not present with multiple adenomas, simply because the first one or two adenomas to occur progress to cancer. Many of these patients will die, or subsequent surgery may reduce adenoma incidence, particularly if large sections of the colon are removed. These factors may combine to give the false appearance that multiple or early onset adenomas are not common in carriers of HNPCC mutations.

Similar factors may have influenced the data of Jass $e t a t^{6}$ and caused their at-risk members of HNPCC families to contain fewer individuals with germline HNPCC mutations, thereby potentially obscuring any association between adenomas and HNPCC. Despite this, there are suggestions in the data of Jass et al that members of HNPCC families do develop earlier adenomas. Detailed statistical analysis of the results of Jass et al is not possible from the published data. It is possible, however, to carry out a crude 
TABLE 2 Data of Fass et al ${ }^{6}$ showing adenoma numbers in HNPCC and non-HNPCC family members and age of screening

\begin{tabular}{llll}
\hline & \multicolumn{2}{l}{ Total adenomas } & \\
\cline { 2 - 3 } & $\begin{array}{l}\text { At-risk members of } \\
\text { HNPCC families }\end{array}$ & $\begin{array}{l}\text { Controls from } \\
\text { necropsies }\end{array}$ & Total \\
\hline Age $<50$ & 28 & 6 & 34 \\
Age $>50$ & 24 & 55 & 79 \\
Total & 52 & 61 & 113 \\
\hline
\end{tabular}

$\chi_{1}^{2}=25.8, \mathrm{p}<0.0001$

The data are uncorrected for sex or multiple polyps within one individual. Nevertheless, the highly significant $\chi^{2}$ value obtained suggests that an association does exist despite the use of uncorrected data.

analysis. Consider, for example, patients presenting before 50 years of age as a separate group (table 2): age of onset of colon cancer before 50 years is a criterion for diagnosing HNPCC. There is evidence in the data of Jass $e t$ al of a strong assocation between earlier onset of adenomas and being a member of an HNPCC family (table 2). It is very likely that those who present earlier with adenomas also have more adenomas in their lifetime. It was simply not possible for Jass et al to consider lifetime risk in their study. We suggest, therefore, that there is some increased risk of adenomas in HNPCC families. Although this seems unlikely to be a large increase, it is certainly consistent with the model of adenoma development outlined earlier, in which there is a greater chance of two APC mutations occurring in a patient with a germline HNPCC mutation than in the general population.

Whatever their more subtle effects, germline HNPCC mutations do not seem, from our data, to be a general cause of multiple colonic adenomas (or of the early onset or several adenomas found in some of our patients). The problem remains of what does cause multiple adenomas. Some undetected APC mutations may be responsible: in addition to early exon mutations, ${ }^{21}$ recent findings suggest that mutations at the extreme 3 ' end of the APC gene can cause AAPC. ${ }^{22}$ There is, however, scope for the existence of adenoma predisposing genes that have not yet been characterised. Families have been reported with multiple colonic adenomas, but no genetic evidence of FAP, AAPC, or HNPCC. ${ }^{92}$ It may be useful to exclude germline APC mutations from such families before undertaking genetic mapping, although our data suggest that similar exclusion of HNPCC mutations may not be worthwhile.

The absence of germline HNPCC mutations in patients with a predisposition to colorectal adenomas is an important negative result. Firstly, individuals with adenomas, however many their number, should not strictly be classified as "affected" in putative HNPCC families. Carcinoma alone should define this status (notwithstanding the fact that carriers of germline mismatch repair mutations may be at greater risk than the general population of developing colorectal adenomas and that members of HNPCC families with adenomas should therefore receive appropriate screening). Secondly, families and individuals with adenomas (and without germline APC mutations) may require different screening from patients with FAP, AAPC, or HNPCC: it is currently difficult to be certain of the precise form that this screening should take, but screening for gynaecological cancers-for example, is probably unnecessary in families with adenomas only. Thirdly, it is probably not worthwhile performing diagnostic or predictive genetic testing for HNPCC mutations in individuals with multiple colon adenomas, in the absence of a personal or strong family history of colorectal or other HNPCC associated cancer.

We are grateful to the patients and to several clinicians, notably Dr C B Williams, from St Mark's Hospital, London, and the Polyposis Registry for supplying samples from, and the clinical details of, many of these patients.

1 Lynch HT, Smyrk T, Lynch JF. Overview of natural history, pathology, molecular genetics and management of

2 Liu B, Nicolaides NC, Markowitz S, et al. Mismatch repair gene defects in sporadic colorectal cancers with microsatelgene defects in sporadic colorectal cancers

3 Nagase H, Nakamura Y. Mutations of the APC (adenomatous polyposis coli) gene. Hum Mutat 1993; 2: 425-34.

4 Reitmair AH, Cai JC, Bjerknes M, et al. MSH2 deficiency contributes to accelerated APC-mediated intestinal tumorigenesis. Cancer Res 1996; 56: 2922-6.

5 Miyaki M, Tanaka K, Kikuchi YR, Muraoka M, Konishi M. Familial polyposis: recent advances. Crit Rev Oncol Hematol 1995; 19: 1-31.

6 Jass JR, Stewart SM, Stewart J, Lane MR. Hereditary nonpolyposis colorectal cancer-morphologies, genes and mutations. Mutat Res 1994; 310: 125-33.

7 Parsons R, Li GM, Longley M, et al. Mismatch repair deficiency in phenotypically normal human cells. Science 1995; 268: $738-40$.

8 Liu B, Parsons R, Papadopoulos N, et al. Analysis of mismatch repair genes in hereditary nonpolyposis colorecmismatch repair genes in hereditary nonpolyp

9 Tomlinson IPM, Beck NE, Homfray T, et al. Molecular and clinico-pathological features of two families with the HNPCC syndrome and unusual phenotypes. GI Cancer (in press).

10 Shibata D, Peinado MA, lonov Y, Malkhosyan S, Perucho $M$. Genomic instability in repeated sequences is an early somatic event in colorectal tumorigenesis that persists after transformation. Nat Genet 1994; 6: 273-81.

11 van der Luijt $\mathrm{R}$, Khan PM, Vasen $\mathrm{H}$, et al. Rapid detection of translation-terminating mutations at the adenomatous polyposis-coli (APC) gene by direct protein truncation test. Genomics 1994; 20: 1-4.

12 Beck NE, Tomlinson 1PM, Homfray T, et al. Germ-line HNPCC mutations in families fulfilling the Amsterdam criteria. Hum Genet 1997 (in press).

13 Goessl C, Pistorius S, Frank S, Nagel M, Saeger HD, Schackert HK. Techniques and stratgies for identification of mutations predisposing to hereditary nonpolyposis of mutations predisposing to hereditary nonpolyposis becks Arch Chir 1996; S1: 353-6.

14 Papadopoulos N, Leach FS, Kinzler KW, Vogelstein B. Monoallelic mutation analysis (MAMA) for identifying germline mutations. Nat Genet 1995; 11: 99-102.

15 Ushijima T, Hosoya Y, Suzuki T, Sofuni T, Sugimura T, Nagao M. A rapid method for detection of mutations in the lacI gene using PCR-single strand conformation polymorphism analysis: demonstration of its high sensitivity. Mutat Res 1995; 334: 283-92.

16 Ravnik GM, Glavac D, Dean M. Sensitivity of single-strand conformation polymorphism and heteroduplex method for mutation detection in the cystic fibrosis gene. Hum Mol Genet 1994; 3: 801-7.

17 Vidal PA, Moller DE. Comparative sensitivity of alternative single-strand conformation polymorphism (SSCP) methods. Biotechniques 1994; 17: 490-2.

18 Sheffield VC, Beck JS, Kwitek AK, Sandstrom DW, Stone EM. The sensitivity of single-strand conformation polymorphism analysis for the detection of single base substitutions. Genomics 1993; 16: 325-32.

19 Tomlinson IPM, Beck NE, Homfray T, Harocopos CJ, Bodmer WF. Germline HNPCC gene variants have little influence on the risk of sporadic colorectal cancer. $f \mathrm{Med}$ Genet 1997; 34: 39-42.

20 Young J, Leggett B, Gustafson C, et al. Genomic instability occurs in colorectal carcinomas but not in adenomas. Hum Mutat 1993; 2: 351-4.

21 Spirio L, Olschwang S, Groden J, et al. Alleles of the APC gene: an attenuated form of familial polyposis. Cell 1993; 75: $951-7$.

22 Friedl W, Meuschel S, Caspari R, et al. Attenuated familial adenomatous polyposis due to a mutation in the $3^{\prime}$ part of the APC gene. A clue for understanding the function of the the APC gene. A clue for understanding the

23 Stella A, Resta N, Gentile M, et al. Exclusion of the APC gene as the cause of a variant form of familial adenomatous polyposis (FAP). Am f Hum Genet 1993; 53: 1031-7. 